\title{
Prevalence, Demographic Characteristics and Comorbid Psychiatric Disorders in Children and Adolescents With Substance Use Disorder in Iran
}

\section{Mohammad Reza Mohammadi}

Tehran University of Medical Sciences

Seyed Kaveh Hojjat ( $\sim$ s.kavehhojjat1@gmail.com )

Mashhad University of Medical Sciences https://orcid.org/0000-0002-5408-0179

\section{Ali Khaleghi}

Tehran University of Medical Sciences

\section{Zahra Hooshyari}

Tehran University of Medical Sciences

\section{Seyed-Ali Mostafavi}

Tehran University of Medical Sciences

\section{Seyed Salman Alavi}

Tehran University of Medical Sciences

\section{Nastaran Ahmadi}

Yazd University of Medical Science: Shahid Sadoughi University of Medical Sciences and Health Services

\section{Faezeh kaviyani}

North Khorasan University of Medical Sciences

\section{Ameneh Ahmadi}

Tehran University of Medical Sciences

\section{Alireza Armani Kian}

Zanjan University of Medical Sciences

\section{Nasrin Sarraf}

Qazvin University of Medical Sciences

\section{Parvin Safavi}

Shahrekord University of Medical Science

Mina Norozi Khalili

North Khorasan University of Medical Sciences

\section{Siavash Talepasand}

Semnan University

\section{Shahrokh Amiri}

Tabriz Medical University: Tabriz University of Medical Sciences

\section{Parviz Molavi}

Ardabil University of Medical Sciences: Ardebil University of Medical Sciences

\section{Hadi Akbari}

North Khorasan University of Medical Sciences 


\section{Soroor Arman}

Isfahan University of Medical Sciences

\section{Soleiman Mohammadzadeh}

Kurdistan University of Medical Science: Kurdistan University of Medical Sciences

\section{Maryam Kousha}

Guilan University of Medical Sciences

\section{Atieh Golbon}

Hormozgan University of Medical Sciences

\section{Seyed Hamzeh Hosseini}

Mazandaran University of Medical Sciences

\section{Ali Delpisheh}

Ilam University of Medical Sciences

\section{Azizollah Mojahed}

Zahedan University of Medical Sciences

\section{Fatemeh Moharari}

Mashhad University of Medical Sciences

\section{Reza Dastjerdi}

Birjand University of Medical Sciences

\section{Nasrin Jaberghaderi}

Kermanshah University of Medical Sciences

\section{Rahim Ostovar}

Yasuj University of Medical Sciences

\section{Mehriar Nadr Mohammadi Moghadam}

Ardabil University of Medical Sciences: Ardebil University of Medical Sciences

\section{Maryam Salmanian}

Tehran University of Medical Sciences

\section{Hadi Zarafshan}

Tehran University of Medical Sciences

\section{Research}

Keywords: Substance use disorder, Children and adolescents, Comorbidity, Prevalence

Posted Date: June 15th, 2021

DOI: https://doi.org/10.21203/rs.3.rs-582529/v1

License: (c) (i) This work is licensed under a Creative Commons Attribution 4.0 International License. Read Full License 


\section{Abstract}

Background: The present study aimed to investigate the prevalence of substance use disorder in Iranian children and adolescents and its relationship with demographic characteristics and psychiatric comorbidities.

Method: The data were taken from a national survey on the prevalence of psychiatric disorders in Iranian children and adolescents. The national survey was conducted on 30,532 children and adolescents aged 6-18 years. The psychiatric disorders were assessed by employing k-SADS-PL questionnaire and interviews carried out by 240 clinical psychologists with the participants and their parents. Data were analyzed by Chi-square test and logistic regression.

Results: A total of $277(0.97 \%)$ were diagnosed as people with substance use disorder which were further studied for comorbid disorders. Among the various types of drugs, hypnotic / sedative / anti-anxiety drugs were abused by 84 people $(46.15 \%)$, cannabis by $68(37.36 \%)$ and stimulants by $43(23.63 \%)$. The variables of gender, place of residence, and father's occupation and parents' education level were identified as predictors of substance use disorder in children and adolescents. At the same time, $42.50 \%$ substances and alcohol abusing people had at least one comorbid psychiatric disorder and the highest Comorbidity was observed in oppositional defiant disorder, attention deficit and hyperactivity disorder and separation anxiety disorder $(p \leq 0.05)$.

Conclusions: The findings can be used in the prevention and treatment of substance use disorder and promotion of mental health in children and adolescents by focusing on the psychiatric comorbidities of people with substance use disorder.

\section{Highlights}

- The findings of this study showed the prevalence of substance use disorder among Iranian children and adolescents was $(0.97 \%)$.

- The variables of gender, place of residence, and father's occupation and parents' education level were identified as predictors of substance use disorder in children and adolescents.

- In children and adolescents with substances and alcohol abuse, $42.50 \%$ had at least one other comorbid psychiatric disorder.

\section{Introduction}

Unhealthy behaviors such as smoking and alcohol/drugs abuse often begin in adolescence [1]. These behaviors create a major challenge to the public health because they increase mortality and morbidity rate [2]. Despite the prohibition of drug use, evidence suggests that the consumption of alcohol, tobacco, and marijuana is considerable among adolescents aged 12 to 17 years[3]. In the United States, about half of 18-year-old adolescents have consumed narcotics at least once in their lives [4]. In Europe, on average, $21 \%$ of boys and $15 \%$ of girls aged 15 to 16 have used illegal drugs at least once in their lives [5]. A longitudinal study indicates a high prevalence of alcohol, marijuana and cigarette smoking in adolescents in Europe (34.1\%) [6]. Evidence suggests that drug use among adolescents has increased dramatically in Iran [7-9]. The results of Momtazi \& Rawson's study on Iranian students showed at least one instance of alcohol use in the lifetime of students $(9.90 \%)$ and prevalence of substance use disorder about $1.20 \%$ and $6.60 \%$ in different regions of Iran [10]. 
Mohammadkhani's study showed that cigarettes (14.70\%) and alcoholic beverages (9.80\%) were the most prevalent materials used in lifetime of Iranian students and the prevalence of other substances was 2.50\% [7].

Another concern of the study the connection between substance abuse and the existence of psychiatric comorbidities in adolescence. A key factor for understanding the causes, history and treatment of substance abuse is knowing the comorbidities associated with substance abuse [11]. Some studies have also shown that drug abuse is related to psychiatric disorders such as oppositional defiant disorder, hyperactivity and attention deficit disorder, behavioral disorders, depression and anxiety [12-16].. Between 55 and 88 percent of adolescents with substance abuse show the criteria for one of the psychiatric disorders such as functional disorder, depression, anxiety or hyperactivity [17].

Research has shown that comorbid psychiatric disorders in adolescents is associated with higher levels of functional disorder including legal problems, mental health issues, family functioning problems, mixed abuse of drugs, and poor outcome of treatment $[18,19]$.

The purpose of this study was to determine the status of substance use disorder in children and adolescents in related to the demographic characteristics (e.g. age, gender, place of residence, occupation and education of parents) and to investigate the likelihood of associated comorbidities. Childhood and adolescence is the critical period of life determining the health and well-being of society in future. Due to the fact Iran has situated in a special geographical area (a potential region for drug trafficking rout) the status of substance use disorder particularly in children and adolescence needs to be consistently examined. In addition, there is not adequate information about the prevalence of different types of substance abuse in this population. It should be noted that the current study was first of its kind in magnitude and data collection in Iran. Not only it focuses on the prevalence of substance use disorder in children and adolescence, it also targets the comorbid disorders in children and adolescence with substance use disorder. The current study was conducted in two stages. First substance use disorder in children and adolescents was studied in relation to age, gender, place of residence, occupation and education of parents and second, the probability of other psychiatric comorbidities was studied. The results of the study would help us to have better assessment of substance use disorder and the comorbid disorders (particularly in Iranian population) for guiding prevention and treatment policies.

\section{Methods And Materials}

\section{Sampling}

The national cross-sectional survey was conducted on 30,532 children and adolescents in 29 provinces in Iran. Multistage cluster sampling method was used and on average 1000 people were selected from each province. In addition to the main cities, participants from the rural population of each city were randomly selected (using cluster sampling). For this study, the counties and the villages of the subsidiary were divided into 167 clusters based on the postcodes. Then the clusters were divided into blocks of six and in each block one girl and one boy from each age group of 9-6, 10-14, and 15-18 years old were included (for more information on the sampling method see [20].

\section{Data Collection}


Initially, eight clinical psychologists and a total of 240 psychologists were selected from each province. Next, these psychologists were trained how to use Kiddie-SADS-Present and Lifetime Version (K-SADS-PL) questionnaire for the purpose of the study. The trained clinical psychologists identified the eligible people and invited their parents to participate in the study. For being eligible the participants needed to be within the age ranges of 6-10, 10-14, and 14-18 and number of participants in each age range needed be equal. It should be noted that K-SADS-PL was based on DSM IV criteria. Due to the fact we considered four criteria for diagnosing substance use disorder, it can be argued that the substance use disorder in the current study was in the range of moderate intensity in terms of DSM V criteria.

After obtaining consent from the parents, demographic data were collected from children and adolescents. To collect demographic data, participants were asked questions about age, place of residence, parents' occupations, and parents' education level. Afterwards, K-SADS-PL questionnaires were completed on the basis of the interviews with participants. In case of participants under 11 years old both participants and their parents were interviewed using K-SADS-PL but for those above 11, the participants were interviewed directly the using the same instrument. The location of the interviewers and their place in the designated clusters were monitored every day by the provincial observers via the Internet locator (GPS). The provincial observers had been assigned to monitor the data collection process to ensure data are collected in line with data collection procedures.

\section{Instrument}

\section{Semi-structured diagnostic interview by the help of Kiddie-SADS-Present and Lifetime Version}

This semi-structured interview was designed to assess the current and past episodes of mental illness in children and adolescents. It included 5 groups of diagnosis: (1) mood disorders including depression disorders (major depression and dysthymia), mania, and hypomania (2) psychotic disorders, 3) anxiety disorders including social phobia, agoraphobia, specific phobia, obsessive-compulsive disorder, separation anxiety disorder, general anxiety disorder, panic disorder and post-traumatic stress disorder (4) behavioral disorders including ADHD, conduct disorder, oppositional defiant disorder and (5) drug abuse, tick disorders, eating disorders and elimination disorder [21]. The interview questions were based on items of Kiddie-SADS-Present and Lifetime questionnaire. This questionnaire bases the diagnosis on the fourth diagnostic manual for mental illness and its third revision. Interviews start with questions about demographic information. In addition, information on previous psychiatric problems can also be obtained [22]. The completion of the questionnaires was based on information from interviews with parents and children and all other available resources.

The Persian version of this questionnaire had high sensitivity and indices of 0.81 and 0.69 have been reported for its validity of and test-retest reliability [20]. In a study, Kappa coefficient was reported $0.93(<0.001 p)$ for emotional disorders, 0.9 ( $p<0.001)$ for anxiety disorders, and $0.94(p<0.001)$ for ADHD and behavioral disorders [23]. In the current study, the reliability of instrument was also estimated using internal consistency measure of Cronbach's Alpha which indicated adequate reliability $(a>0.70)$.

\section{Analysis}

Data collected from the provinces of Iran were screened by removing the cases with incomplete information. To study the variables related to demographic characteristics, frequency statistics using Chi Square was employed. Logistic regression was also used to determine predictors of substance use disorder with confidence interval of 
95\%. The independent variables for predicting substance use disorder included demographic characteristics and psychiatric comorbidities.

\section{Results}

A total of 30532 children and adolescents aged 6-18 years participated in this cross-sectional study. Out of 30532 participants, 28,540 people were included in the study, and the rest were excluded due to incomplete information about substance abuse. Furthermore, 13936 (48.80\%) were girls and 14604 (51.20\%) were boys. With regard to place of residence, 23829 (83.50\%) were living in cities and 4711 (16.50\%) in villages. The overall prevalence of in children and adolescents was $28.2 \%$. Overall, $28.20 \%$ of the participants were suffering from psychiatric disorders.

In this study, a total of 277 participants were identified as people with substance use disorder. Table 1 shows the prevalence of any unprescribed use among children and adolescents. The use of hypnotic/sedative/anti-anxiety drugs was seen in 84 cases (46.15\%), cannabis in 68 cases (37.36\%) and stimulants in 43 cases (23.63\%), all of which had the highest prevalence among other drugs.

Table 1

The ratio of each drug to the total sample and consumers

\begin{tabular}{|c|c|c|c|}
\hline Type of Drug & $\mathbf{N}$ & $\begin{array}{l}\text { Relative to the } \\
\text { whole sample (\%) }\end{array}$ & $\begin{array}{l}\text { Relative to the } \\
\text { consumers (\%) }\end{array}$ \\
\hline Cannabis (Marie, Pot, Hash) & 68 & $0.24(0.19-0.3)$ & $\begin{array}{l}37.36(30.66- \\
44.58)\end{array}$ \\
\hline Stimulants (Speed, Amphetamine, Crystal, Slimming Pills) & 43 & $0.15(0.11-0.2)$ & $\begin{array}{l}23.63(18.04- \\
30.31)\end{array}$ \\
\hline $\begin{array}{l}\text { Hypnotic/sedative/antianxiety drugs } \\
\text { (Barbiturates, Benzodiazepines, Diazepam, Oxazepam, } \\
\text { Lorazepam, Alprazolam (Xanax)) }\end{array}$ & 84 & $0.29(0.23-0.36)$ & $\begin{array}{l}46.15(39.06- \\
53.40)\end{array}$ \\
\hline Heroin & 21 & $0.07(0.05-0.11)$ & $11.54(7.67-17)$ \\
\hline $\begin{array}{l}\text { Opioids (Opium / Sheere / Heroin / Morphine / Methadone } \\
\text { / Codeine / Pethidine) }\end{array}$ & 31 & $0.11(0.08-0.16)$ & $\begin{array}{l}17.03(12.26- \\
23.16)\end{array}$ \\
\hline PCP (Phencyclidine) / Angel Power & 20 & $0.07(0.05-0.11)$ & $\begin{array}{l}10.99(7.23- \\
16.36)\end{array}$ \\
\hline $\begin{array}{l}\text { Hallucinogenic material (LSD / Acid / Mescaline / Peyote } \\
\text { / Mushroom }\end{array}$ & 26 & $0.09(0.06-0.13)$ & $\begin{array}{l}14.29(9.94- \\
20.11)\end{array}$ \\
\hline $\begin{array}{l}\text { Solvents or inhalants materials (glue / gasoline / } \\
\text { chloroform / ether / colorants) }\end{array}$ & 14 & $0.05(0.03-0.08)$ & $7.69(4.64-12.49)$ \\
\hline $\begin{array}{l}\text { Others (prescribed drugs / Nitrous Oxide / Ecstasy / } \\
\text { Methylene / Amphetamine, etc.) }\end{array}$ & 30 & $0.11(0.08-0.16)$ & $\begin{array}{l}16.48(11.79- \\
22.55)\end{array}$ \\
\hline
\end{tabular}

* There is overlap across different types of substance abuse 
The results of the chi square test (see Table 2) show the prevalence of substance use disorder in boys $(n=193$, $\mathrm{p}=1.6,95 \% \mathrm{cl}=1.39-1.91)$ and girls $(\mathrm{n}=84, \mathrm{p}=0.7,95 \% \mathrm{cl}=0.6-0.9)$. The results of this study evaluated the prevalence of substance use disorder in urban society $(n=251, p=1.2,95 \% \mathrm{cl}=1.06-1.4)$ and in the three age groups; the age group 6-9 years old $(n=53, p=0.6,95 \% \mathrm{cl}=0.4-0.8), 10-14$ years old $(n=67, p=0.9,95 \% \mathrm{cl}=$ $0.7-1.2)$, and $15-18$ years old, $(n=157, P=1.7,95 \% \mathrm{cl}=1.4-2.1)$. The prevalence of substance use disorder in rural population was not taken into account as the total number of people with substance use disorder were so small $(n=26)$ 
Table 2

Distribution of Substance and alcohol use based on Socio-Demographic characteristics

\begin{tabular}{|c|c|c|c|c|c|c|}
\hline \multicolumn{2}{|c|}{ Socio-Demographic Characteristics } & \multicolumn{2}{|l|}{ Total } & \multicolumn{3}{|c|}{$\begin{array}{l}\text { With Substance and alcohol use } \\
\text { disorder }\end{array}$} \\
\hline & & $\mathbf{N}$ & $\%$ & $\mathbf{n}$ & Crude \% & $\%(95 \% \mathrm{Cl})$ \\
\hline \multirow[t]{2}{*}{ Gender } & Boy & 13936 & 48.8 & 193 & 1.4 & $1.6(1.39-1.91)$ \\
\hline & Girl & 14604 & 51.2 & 84 & 0.6 & $0.7(0.6-.09)$ \\
\hline \multirow[t]{3}{*}{ Age } & $6-9$ & 9804 & 34.4 & 53 & 0.5 & $0.6(.4-.8)$ \\
\hline & $10-14$ & 9993 & 35 & 67 & 0.7 & $0.9(.7-1.2)$ \\
\hline & $15-18$ & 8735 & 30.6 & 157 & 1.8 & $1.7(1.4-2.1)$ \\
\hline \multirow[t]{2}{*}{ Types of residence } & Urban & 23829 & 83.5 & 251 & 1.1 & $1.2(1.06-1.4)$ \\
\hline & Rural & 4711 & 16.5 & 26 & 0.6 & $0.8(0.46-1.25)$ \\
\hline \multirow[t]{7}{*}{ Father educations } & Illiterate & 1222 & 4.5 & 18 & 1.5 & $2.3(1.43-3.73)$ \\
\hline & primary school & 4332 & 15.9 & 53 & 1.2 & $1.6(1.1-2.1)$ \\
\hline & $\begin{array}{l}\text { Guidance \& high } \\
\text { school }\end{array}$ & 6113 & 22.4 & 66 & 1.1 & $1.4(1.07-1.81)$ \\
\hline & Diploma & 8010 & 29.3 & 68 & 0.8 & $1(0.74-1.25)$ \\
\hline & bachelor & 5763 & 21.1 & 34 & 0.6 & $0.6(0.44-1)$ \\
\hline & MSc or higher & 1888 & 6.9 & 11 & 0.6 & $0.5(0.26-1.1)$ \\
\hline & Missing & 1212 & & 27 & & \\
\hline \multirow[t]{7}{*}{ Mother educations } & Illiterate & 1620 & 5.9 & 29 & 1.8 & $2.4(1.6-3.6))$ \\
\hline & primary school & 5162 & 18.7 & 58 & 1.1 & $1.5(1.1-2)$ \\
\hline & $\begin{array}{l}\text { Guidance \& high } \\
\text { school }\end{array}$ & 5324 & 19.3 & 54 & 1 & $1.4(1-1.9)$ \\
\hline & Diploma & 9176 & 33.2 & 60 & 0.7 & $0.8(0.6-1)$ \\
\hline & Bachelor & 5367 & 19.4 & 42 & 0.8 & $0.8(0.6-1.2)$ \\
\hline & MSc or higher & 969 & 3.5 & 8 & 0.8 & $1.2(0.6-2.3)$ \\
\hline & Missing & 922 & & 26 & & \\
\hline \multirow[t]{4}{*}{ Father occupation* } & unemployed & 924 & 3.4 & 29 & 3.1 & $3.9(2.6-5.7)$ \\
\hline & Laborer & 15776 & 57.6 & 146 & 0.9 & $1.1(0.9-1.34)$ \\
\hline & Farmer & 924 & 3.4 & 4 & 0.4 & $0.7(0.2-1.9)$ \\
\hline & businessman & 1005 & 3.7 & 13 & 1.3 & $1.7(1-3)$ \\
\hline
\end{tabular}

* $₫ 2=60.969, \mathrm{p}$ value $<0.0001, * \star \otimes 2=12.855, \mathrm{p}$ value $<0.045$ 


\begin{tabular}{|c|c|c|c|c|c|c|}
\hline \multicolumn{2}{|c|}{ Socio-Demographic Characteristics } & \multicolumn{2}{|l|}{ Total } & \multicolumn{3}{|c|}{$\begin{array}{l}\text { With Substance and alcohol use } \\
\text { disorder }\end{array}$} \\
\hline & & $\mathbf{N}$ & $\%$ & $\mathrm{n}$ & Crude \% & $\%(95 \% \mathrm{Cl})$ \\
\hline & Retired & 1564 & 5.7 & 12 & 0.8 & $0.5(0.24-1.28)$ \\
\hline & public sector & 6261 & 22.9 & 42 & 0.7 & $0.7(0.5-1)$ \\
\hline & Teacher & 767 & 2.8 & 5 & 0.7 & $1(0.4-2.5)$ \\
\hline & faculty member & 169 & 0.6 & - & - & \\
\hline & Missing & 1150 & & 26 & & \\
\hline \multirow{8}{*}{$\begin{array}{l}\text { Mother } \\
\text { occupation** }\end{array}$} & housewife & 23574 & 85 & 224 & 1 & $1.2(1-1.4)$ \\
\hline & Laborer & 962 & 3.5 & 4 & 0.3 & $0.2(0.03-0.9)$ \\
\hline & businessman & 218 & 0.8 & 3 & 1.4 & $1.6(0.5-5.7)$ \\
\hline & Retired & 208 & 0.8 & 5 & 2.4 & $4.8(2.24-10.16)$ \\
\hline & public sector & 1604 & 5.8 & 8 & 0.5 & $0.5(0.2-1.1)$ \\
\hline & Teacher & 1089 & 3.9 & 8 & 0.7 & $0.8(0.3-1.7)$ \\
\hline & faculty member & 72 & 0.3 & - & - & \\
\hline & Missing & 813 & - & 25 & & \\
\hline \multicolumn{2}{|l|}{ Total } & 28540 & 100 & 277 & 1 & $143(1-1.3)$ \\
\hline
\end{tabular}

The prevalence of drug and alcohol use in relation to parents' education levels was also measured in six levels of illiteracy, primary school, guidance/high school, Diploma, bachelor degree, and master degree using chi square. The results of chi square test showed a significant relationship between substance/alcohol abuse and father's occupation ( $p$ value $<0.0001$ ) and between substance/alcohol abuse and mother's occupation ( $p$ value $<0.045$ ) (see Table 2). In other words, the parents' type of occupation was significantly related to substance/alcohol abuse in children and adolescence (see discussion section for more details).

\section{The relationship between demographic characteristics and drug and alcohol consumption in children and adolescents}

Logistic regression analysis was used to identify the relationship between demographic characteristics and drug/alcohol consumption among children and adolescents. Table 3 shows that there is a significant relationship between the substance use disorder and $\operatorname{sex}(p=0.001)$. The odds ratio (OR) observed in relation to sex for girls was 0.41 , which indicates that the risk of substance use disorder in girls is lower than boys $(95 \%, \mathrm{Cl}$ $=0.306-0.566)$. There was also a significant relationship between substance use disorder $(p<0.0001)$ and age group. The age range of 15 to 18 years old with a prevalence of $1.7 \%$ and $O R=3.39$ had the highest probability rate of substance use disorder $(95 \%, \mathrm{Cl}=2.302-4.997)$. Another variable that was significantly related to 
substance use disorder was parents' level of education. The rate of substance use disorder is lowered when parents' education level is increased. The rate of substance use disorder when fathers have education level higher than bachelor degree was $\mathrm{OR}=0.20(\mathrm{p}=0.004,95 \%, \mathrm{Cl}=0.068-0.602)$ fathers with bachelor degree $\mathrm{OR}=$ $0.33(\mathrm{p}=0.007,95 \%, \mathrm{Cl}=2.302-4.997)$, and mothers with high school diploma $\mathrm{OR}=0.49(\mathrm{p}=0.030,95 \%, \mathrm{Cl}=$ 0.263-0.934) (see Table 3). 
Table 3

Odds Ratios $(95 \% \mathrm{Cl}$ ) for Substance and alcohol use based on Socio-Demographic Characteristics

\begin{tabular}{|c|c|c|c|c|c|c|c|c|}
\hline \multicolumn{3}{|c|}{ Variables and their categories } & \multicolumn{3}{|c|}{ Univariate } & \multicolumn{3}{|l|}{ Multivariate } \\
\hline & & & $\begin{array}{l}\text { OR } \\
\text { (crude) }\end{array}$ & $\mathrm{Cl}(95 \%)$ & $\begin{array}{l}\text { P- } \\
\text { value }\end{array}$ & $\begin{array}{l}\text { OR } \\
\text { (adjusted) }\end{array}$ & $\begin{array}{l}\mathrm{Cl} \\
(95 \%)\end{array}$ & $\begin{array}{l}\text { P- } \\
\text { value }\end{array}$ \\
\hline \multirow[t]{17}{*}{$\begin{array}{l}\text { Demographic } \\
\text { variables }\end{array}$} & Sex & male & $\begin{array}{l}1.00 \\
\text { Baseline }\end{array}$ & & & & & \\
\hline & & female & 0.430 & $.322-.574$ & $\begin{array}{l}<.0001 \\
0.0\end{array}$ & 0.416 & $\begin{array}{l}0.306- \\
0.566\end{array}$ & 0.001 \\
\hline & $\begin{array}{l}\text { Age } \\
\text { group }\end{array}$ & $6-9$ & $\begin{array}{l}1.00 \\
\text { Baseline }\end{array}$ & & & & & \\
\hline & & $10-14$ & 1.52 & $\begin{array}{l}1.02- \\
2.26\end{array}$ & .042 & 1.359 & $\begin{array}{l}.884- \\
2.09\end{array}$ & 0.166 \\
\hline & & $15-18$ & 3.61 & $\begin{array}{l}2.51- \\
5.20\end{array}$ & $\begin{array}{l}<.0001 \\
0\end{array}$ & 3.392 & $\begin{array}{l}2.302- \\
4.997\end{array}$ & $\begin{array}{l}<.0001 \\
0.00\end{array}$ \\
\hline & $\begin{array}{l}\text { place of } \\
\text { residence }\end{array}$ & Urban & $\begin{array}{l}1.00 \\
\text { Baseline }\end{array}$ & & & & & \\
\hline & & Rural & 0.643 & $\begin{array}{l}0.382- \\
1.082\end{array}$ & 0.096 & 0.479 & $\begin{array}{l}0.277- \\
0.827\end{array}$ & 0.008 \\
\hline & $\begin{array}{l}\text { Father } \\
\text { education }\end{array}$ & Illiterate & $\begin{array}{l}1.00 \\
\text { Baseline }\end{array}$ & & & & & \\
\hline & & $\begin{array}{l}\text { primary } \\
\text { school }\end{array}$ & 0.671 & $\begin{array}{l}0.373- \\
1.204\end{array}$ & 0.181 & 0.879 & $\begin{array}{l}0.465- \\
1.662\end{array}$ & 0.692 \\
\hline & & $\begin{array}{l}\text { High } \\
\text { school }\end{array}$ & 0.594 & $\begin{array}{l}0.339- \\
1.042\end{array}$ & 0.069 & 0.829 & $\begin{array}{l}0.430- \\
1.597\end{array}$ & 0.575 \\
\hline & & Diploma & 0.403 & $\begin{array}{l}0.230- \\
0.707\end{array}$ & 0.002 & 0.588 & $\begin{array}{l}0.291- \\
1.188\end{array}$ & 0.139 \\
\hline & & Bachelor & 0.272 & $\begin{array}{l}0.145- \\
0.512\end{array}$ & $\begin{array}{l}< \\
0.0001\end{array}$ & 0.331 & $\begin{array}{l}0.148- \\
0.742\end{array}$ & 0.007 \\
\hline & & $\begin{array}{l}\text { MSc or } \\
\text { higher }\end{array}$ & 0.217 & $\begin{array}{l}0.088- \\
0.534\end{array}$ & 0.001 & 0.203 & $\begin{array}{l}0.068- \\
0.602\end{array}$ & 0.004 \\
\hline & Mother & Illiterate & $\begin{array}{l}1.00 \\
\text { Baseline }\end{array}$ & & & & & \\
\hline & & $\begin{array}{l}\text { primary } \\
\text { school }\end{array}$ & 0.615 & $\begin{array}{l}0.366- \\
1.034\end{array}$ & 0.067 & 0.689 & $\begin{array}{l}0.391- \\
1.216\end{array}$ & 0.199 \\
\hline & & $\begin{array}{l}\text { High } \\
\text { school }\end{array}$ & 0.570 & $\begin{array}{l}0.341- \\
0.952\end{array}$ & 0.032 & 0.637 & $\begin{array}{l}0.347- \\
1.167\end{array}$ & 0.144 \\
\hline & & Diploma & 0.322 & $\begin{array}{l}0.195- \\
0.531\end{array}$ & $\begin{array}{l}< \\
0.0001\end{array}$ & 0.496 & $\begin{array}{l}0.263- \\
0.934\end{array}$ & 0.030 \\
\hline
\end{tabular}

OR adjusted: Odds Ratio, Cl: Confidence Interval 


\begin{tabular}{|c|c|c|c|c|c|c|c|}
\hline & Bachelor & 0.338 & $\begin{array}{l}0.196- \\
0.584\end{array}$ & $\begin{array}{l}<.0001 \\
0\end{array}$ & 0.713 & $\begin{array}{l}0.344- \\
1.479\end{array}$ & 0.363 \\
\hline & $\begin{array}{l}\text { MSc or } \\
\text { higher }\end{array}$ & 0.512 & $\begin{array}{l}0.235- \\
1.118\end{array}$ & 0.093 & 1.506 & $\begin{array}{l}0.575- \\
3.944\end{array}$ & 0.405 \\
\hline
\end{tabular}

\section{Psychiatric comorbidities in children and adolescents consuming substances and alcohol}

The investigation of comorbidities in children and adolescents consuming alcohol and substance showed that in general, $42.5 \%$ of children and adolescents were suffering from comorbid disorders (see Table 4 ). Based on the statistics, substance use disorder had the highest comorbidity with behavioral disorders $(p=22,95 \% \mathrm{Cl}=17-$ 28) and among behavioral disorders oppositional defiant disorder had the highest prevalence $(p=13.7,95 \% \mathrm{Cl}=$ 9.8-18.9). The next highest prevalent comorbid disorder was anxiety disorder $(P=18.8,95 \% \mathrm{Cl}=14.2-24.5)$ and among the anxiety disorders, separation anxiety disorder had the highest prevalence $(p=7.9,95 \% \mathrm{Cl}=4.9-12.1)$. 
Table 4

\begin{tabular}{|c|c|c|c|}
\hline \multicolumn{2}{|l|}{ Psychiatric Disorders } & \multirow[t]{2}{*}{ Number } & \multirow{2}{*}{$\begin{array}{l}\text { Percent } \\
\text { (Cl 95\%) }\end{array}$} \\
\hline & & & \\
\hline \multirow[t]{4}{*}{ Mood Disorders } & Depression & 13 & $3.2(1.6-6.5)$ \\
\hline & Mania & 3 & $2(0.7-4.6)$ \\
\hline & Hypomania & 4 & $3.2(1.6-6.5)$ \\
\hline & Total Mood Disorders & 16 & $5.9(3.5-9.9)$ \\
\hline Psychosis & & 5 & $1.7(0.7-4.6)$ \\
\hline \multirow[t]{9}{*}{ Anxiety Disorders } & Panic Disorder & 2 & $0.5(0.08-2.5)$ \\
\hline & Separation Anxiety & 18 & $7.9(4.9-12.1)$ \\
\hline & Social Phobia & 10 & $2.2(1-5.2)$ \\
\hline & Specific Phobias & 9 & $5.1(2.8-8.8)$ \\
\hline & Agoraphobia & 8 & $4(2.2-7.6)$ \\
\hline & Generalized Anxiety & 14 & $3.2(1.6-6.5)$ \\
\hline & Obsessive Compulsive & 13 & $3.2(1.6-6.5)$ \\
\hline & Post-Traumatic Stress & 12 & $3.2(1.6-6.5)$ \\
\hline & Total Anxiety Disorders & 51 & $18.8(14.2-24.5)$ \\
\hline \multirow[t]{5}{*}{ Behavioral Disorders } & Conduct Disorder & 25 & $10.1(6.8-14.8)$ \\
\hline & ADHD & 20 & $6.3(3.8-10.4)$ \\
\hline & ODD & 38 & 13.7(9.8-18.9) \\
\hline & Tic Disorder & 5 & $4(2.1-7.6)$ \\
\hline & Total Behavioral Disorders & 57 & $22(17-28)$ \\
\hline \multirow[t]{3}{*}{ Neurodevelopmental disorders } & Mental retardation & 21 & $8.2(5.3-12.6)$ \\
\hline & Epilepsy & 11 & $3.6(1.9-7)$ \\
\hline & Total Neurodevelopmental disorders & 30 & $11.5(7.9-16.4)$ \\
\hline Enuresis disorder & & 23 & $6.3(3.9-10.5)$ \\
\hline Total comorbid disorders & & 112 & $42.5(36.3-49.3)$ \\
\hline
\end{tabular}




\section{Discussion}

The aim of this study was to investigate the demographic characteristics of children and adolescents abusing alcohol and drugs and the degree of comorbid psychiatric disorders in Iranian children and adolescents. A total of 277 children and adolescents with substance use disorders were identified. Among this number of children and adolescents, 174 people $(0.73 \%)$ consumed alcohol and 182 people $(0.8 \%)$ had substance use disorders. The results of the previous studies conducted in different regions of Iran, shows the prevalence of $1.2-6.8 \%$ drug abuse and $9.9 \%$ alcohol abuse [10]. Accordingly, we can argue that prevalence of substance use disorder has reduced in Iranian context. Studies conducted around the world show a higher prevalence of substance use disorder than the one in the present study [24-26]. The observed differences with regard to the prevalence of substance use disorder between the studies conducted inside and outside the country can be associated with different factors including increased awareness of the Iranian people through mass media, social media, and formal education. Recently, there is a boost in the use of the social medial applications which has accelerated the rate of information exchanges both in young and adult populations. Furthermore, local mass media frequently warns the parents about the prevalence of substance use disorder in children and adolescence. All these information exchanging vehicles might have heighted the parents and children's awareness about the devastating effects of substance use disorder leading to lower prevalence of substance abuse in Iranian children compared to children in other countries. In other words, the increased awareness about the substance use disorder in children and adolescence can decrease the risk of neglect in children. Previous studies consistently show that negligence put the children at increased risk of substance abuse [27].

The current study showed that anti-anxiety and hypnotic drugs (46.15\%), cannabis (37.36\%) and stimulants (23.63\%) had the highest consumption by children and adolescents. In the study by Gattamorta [14] on Spanish adolescents the prevalence of marijuana $(97 \%)$ was much higher than the that of the present study. However, with regard to the prevalence of anti-anxiety drugs and stimulants, Gattamorta's findings were similar to the findings of the present study. Mesic et al. [25] also showed that the marijuana was the most abused drug among students in Sarajevo and Granica. The study by Mohammadkhani [7] in Iran, which was conducted on 2,537 secondary students, showed that cannabis and ecstasy had the highest prevalence rate in the last month of their study. The differences observed in various studies in the prevalence of different types of substances can be associated with the amount of use or accessibility of substances in different regions, and also to different attitudes toward various types of substances in different cultural and ethnic contexts. Gibbons et al. [28] have pointed to the availability of substances as a variable affecting substance use and Rahimian Boogar et al. [29] found that certain personality traits are connected with positive attitudes and more inclination toward substance abuse. The existence of risk factors in Iranian society (e.g. economical factor, family problems, community disorganization etc.) could pave the way for the formation of positive attitudes toward substance and alcohol abuse as a way to get away from such pressures.

The present study also revealed that there is a significant difference in the prevalence of drug and alcohol consumption between boys and girls $(p=0.001)$. As Table 3 shows, girls are less likely to be affected by substance use disorder than boys. $(\mathrm{OR}=0.430,95.0, \mathrm{c} 1=0.306-0.566)$. In this regard, the Center for Behavioral Health Statistics and Quality (CBHSQ) reported the substance use disorder rate of $4.5 \%$ in girls and $4 \%$ in boys worldwide in 2016. It should be noted that findings of Ljubotina et al. (2004) and review studies $(24,26)$. support the impact of the gender factor on the rate and type of substance abuse. The fact of gender as a predictor of

Page $14 / 21$ 
drug and alcohol abuse can be attributed to cultural and ethnic factors and social beliefs toward the use of drug and alcohol.

According to the results of the current study, the use of drugs and alcohol in the age group of 15-18 years old was significantly different from the two age groups of $6-9$ and $10-14$ years old $(p<0.0001)$. The age group of 15-18 years old also had the highest probability of substance and alcohol abuse $(\mathrm{OR}=3.64,0.95, \mathrm{C} 1=1.944-$ 4.068). Sharmat et al (2018) also confirm a significant positive relationship between the prevalence of drug abuse and age in adolescents [30]. They showed that the prevalence of substance abuse among adolescents increases as they get older.

The present study showed that there is a significant relationship between the level of fathers' education and the prevalence of substance use disorder. The participants whose fathers had a bachelor or higher degree were less likely to be at the risk of drugs and alcohol abuse than others. Table 2 shows the highest prevalence of substance use disorder in families with illiterate parents. A study by Pérez et al. (2018) has shown that low literacy in parents can be a predictor of early substance abuse in adolescents [31]. The family and the school are two main social contexts affecting the social development of the adolescents [31]. Accordinly,parents' literacy as a family factor can directly influence the way adolescen react to their environement. A literate parent may know more about the parental roles, more systmatically deal with the family problems, and know more sources of infomration. All these elements could avoid neglegence and reduce the likelyhood of adolescencs' risky behaviors. In addition, parentes' education could be connected with the socioeconomic status of the family as parents with higher education could have jobs with higher saleries. Studies show that poor socioeconomic status of the family is related to the higher prevelence of risk behaviors in adolecence [32).

Table 2 shows that there is a significant relationship between parents' occupation and the prevalence of substance use disorder in children and adolescents participating in the current study (father's occupation with $\mathrm{p}$ value $<0.0001$ ) and (mother's occupation with $p$ value $<0.045)$. The results of logistic regression analysis indicated that unemployment in fathers can be a predictor of substance use disorder in children and adolescents. Droomers et al. (2003) reported a significant relationship between alcohol consumption and father's occupation in 15-year-old adolescents [33]. According to the results of their study, adolescents whose fathers had lower-level occupations were 2 times more likely than other adolescents to be at the risk of alcohol consumption. On the other hand, Vereecken et al. (2004) did not show parents' occupation is significantly related to alcohol consumption and smoking in adolescents [34]. Also, in the study by Richter et al. (2009) in 28 countries, parents' occupation was not found significantly related to alcohol consumption, smoking and cannabis abuse [35]. Richter et al. (2009) further showed that risky behaviors of children and adolescents are rarely affected by income and social status of parents [35]. Considering the fact that various studies point to the role of individual and environmental factors in high-risk behaviors [36-38] and also the lack of conclusive findings regarding the role of parents' occupation in alcohol and substance abuse in adolescence, it is concluded that parents' occupation as a predictor of substance use disorder in adolescence has a contextual nature. In other words, the way parents' occupation is related to substance use disorder in children and adolescence could vary in different communities.

The present study indicated a psychiatric comorbidity rate of $42.5 \%$ in children and adolescents abusing alcohol and substances [39-41]. Various studies have confirmed the high comorbidity of psychiatric disorders in adolescent with substance use disorder. For example, the study of Welsh et al. (2017) on 483 individuals aged 
11-24, confirms the significant relationship between the use of alcohol, marijuana, opioids and tobacco and some psychiatric disorders [42]. In the same vein, the study of Gattamorta (2017) on adolescents referring to treatment centers showed the comorbidity of psychiatric disorders in adolescents with substance use disorder is $83.2 \%$, which is a high rate of psychiatric disorders in adolescents with substance use disorder [14]. All these evidences including the current study further support the existence of comorbid disorders in people with substance and alcohol use disorder.

In the present study, the highest comorbidity was related to behavioral disorders (22\%), with the highest association with ODD (13.7\%). The study by Gattamorta (2017) revealed that substance use disorder in adolescents is highly comorbid with ODD, OCD, and ADHD, which is in line with the findings of the current study [14]. Also, Razali and Kliewer's study (2015) on 895 adolescents with age average of 17.5 showed that early appearance of antisocial behaviors is a common long-term effect of drug abuse [43]. Based on Molina et al. (2018), early use of alcohol, cigarettes, marijuana and other illegal drugs in adolescents with ADHD was 57\%, which was more than that of the NON-ADHD people (41\%) [15]. The early use alcohol and other illegal substances other than marijuana was also reported in ADHD adolescents [16]. The results of the current study and those of the current one further highlight the importance of comorbid disorders in children and adolescence with substance use disorder. Although such disorders could be present before or along with the substance abuse, it is necessary to deal with them for both prevention and treatment of substance use disorder. For example, Swendsen et al. (2010) reported behavioral disorders as significant risk factors of substance use disorder [44]. Hence, early diagnosis and treatment of these disorders could have positive role in preventing later substance use disorder. Additionally, the co-occurrence of comorbid disorders with substance use disorder would hinder the substance use disorder treatment as comorbid disorders could have been the main risk factors for the substance use disorder.

In the present study, after behavioral disorders, substance use disorder in children and adolescents was highly comorbid with anxiety disorders (18.4\%). Also, the results of this study showed that separation anxiety was associated with substance use disorder more than other anxiety disorders. What is common in all anxiety disorders is an experience of fear and apprehension coupled with various physical symptoms mediated by the autonomic nervous system [45]. Several studies show that different types of drug abuse co-occur with anxiety disorders [44, 46, 47]. A study by Legerstee et al. (2010) found that children with anxiety disorders encounter significantly more unpleasant experiences than their peers which can reduce their function and cause secondary increase in their anxiety [48]. Their study showed that the intensity of anxiety can lead to inappropriate behavior patterns and the use of ineffective coping strategies to deal with anxiety. In explaining the comorbidity of substance use disorder and anxiety disorders, self-regulation theory can be drawn on. Accordingly, it can be mentioned that when a child or teenager experiences anxiety, it is possible that he/she is not consciously capable of managing his/her behavior, thoughts and emotions to use more effective coping strategies. Such lack of self-regulation capacity may impel the children and adolescents toward harmful and destructive behaviors to control their physical and mental stress. Self-regulation can be defined as one's ability to manage emotions, desires, and impulses and it is suggested that poor self-regulation is connected to risky behaviors [49]. Quinn \& Fromme (2010) found that high self-regulation inversely predicts heavy episodic drinking, alcoholrelated problem, and unprotected sex [50].

In the field of mood disorders, several studies have pointed to the comorbidity of mood disorders and substance use disorder between $16 \%$ and $54 \%$ in various studies [51-53]. Such comorbidity rates are more than the one 
observed in the present study (5.9\%). The observed difference may be attributed to the differences in the samples' characteristics, differences in the questionnaire used, and other demographic and socioeconomic characteristics of the groups in the current study.

\section{Limitation}

It is probable that only the most severe cases of substance use disorder have been reported in this study because of the use of KSADS questionnaire. Also, families may have reported fewer cases of alcohol and drug abuse due to their social stigma. Therefore, the prevalence of substance use disorder might be higher than reported levels.

\section{Conclusion}

In general, this study showed that the prevalence of substance use disorder in Iranian children and adolescents was lower than the prevalence of substance use disorder in other studies conducted both inside and outside the country. Additionally, gender, place of residence, age, and the level of parents' education and occupation were found to be predictors of substance use disorder in children and adolescents. With regard to comorbidity, it was found that comorbidity of substance use disorder and psychiatric disorders in Iranian children and adolescents is $42.5 \%$. This highlights the importance of comprehensive mental health assessment for clinical care and treatment of people with substance use disorder. It is particularly concluded that early users of alcohol and drugs need special attention in terms of psychological and psychiatric care and treatment. Since the nature of relationship between psychiatric disorders and substance abuse is not completely known, researchers and therapists are advised to examine how these two categories interact with each other.

\section{Abbreviations}

k-SADS-PL: kiddie schedule for affective disorders and schizophrenia present and lifetime, ODD: Oppositional defiant disorder, OCD: Obsessive-compulsive disorder, ADHD: Attention-deficit/hyperactivity disorder, GPS: Global Positioning System

\section{Declarations}

\section{Declarations}

Informed consent was obtained from all participants prior to the survey.

\section{Consent to publish}

Not applicable.

\section{Availability of data and materials}

Not applicable.

\section{Competing interests}


The authors declare no conflicts of interest.

\section{Funding}

This study was approved by the national institute for medical research development (NIMAD).

\section{Authors' Contributions}

All authors contributed in this study. Provincial implementation and data collection was performed by MR M, SK H, A K, SA M, SS A. N A, A A, A AK, N S, P S, S T, S A, P M, S A, S M, M K, A G, SH H, A L, A M, F M, R D, N J, R O, MN MM, M S. Z H and M NK carried out data analysis, and all others provided critical comments on that. The first draft of the manuscript was written by MR M, SK H, FK and $\mathrm{H}$ A.

\section{Acknowledgments}

The authors acknowledge with grateful appreciation the kind assistance provided by the Vice Chancellor for Research at the North Khorasan University of Medical Sciences. We also thank all the psychologists and colleagues from all the provinces for their collaboration.

\section{Ethical Considerations}

This is to certify that the research proposal entitled "Prevalence and Correlates of Psychiatric Disorders in a National Survey of Iranian Children and Adolescents" with Reg. No. 940906 was approved by ethical committee of national institute for medical research development (NIMAD). The Ethic approval Cod is IR.NIMAD.REC.1395.001.

\section{Conflict of interest}

The authors declare no conflicts of interest.

\section{References}

1. Das JK, Salam RA, Arshad A, Finkelstein Y, Bhutta ZA. Interventions for adolescent substance abuse: An overview of systematic reviews. Journal of Adolescent Health. 2016;59(4):S61-S75.

2. Mangerud WL, Bjerkeset O, Holmen TL, Lydersen S, Indredavik MS. Smoking, alcohol consumption, and drug use among adolescents with psychiatric disorders compared with a population based sample. Journal of Adolescence. 2014;37(7):1189-99.

3. Substance Abuse and Mental Health Services A. CBHSQ Methodology Report. In National Survey on Drug Use and Health: Summary of Methodological Studies, 1971-2014. Rockville (MD): Substance Abuse and Mental Health Services Administration (US). 2014.

4. Johnston L. D. OMPM, Miech R. A., Bachman J. G., \& Schulenberg J. . Monitoring the Future national survey results on drug use: 1975-2015: Overview of key findings on adolescent drug use. 2016. Ann Arbor: Institute for Social Research, The University of Michigan. 2016.

5. Kraus L, Nociar A. ESPAD report 2015: results from the European school survey project on alcohol and other drugs: European Monitoring Centre for Drugs and Drug Addiction; 2016. 
6. Moss HB, Chen CM, Yi H-y. Early adolescent patterns of alcohol, cigarettes, and marijuana polysubstance use and young adult substance use outcomes in a nationally representative sample. Drug and Alcohol Dependence. 2014;136:51-62.

7. Sh M. Prevalence of smoking ,alcohol and psychoactive substances in Iranian adolescents. J Kerman Univ Med Sci. 2011;19(1):32-48.

8. Serajzadeh SHA, Y. Factors influencing Attitudes to -ward Drug Use among College Students (Case of Study: College Students University of Kharazmi) 2014. IAU International Journal of Social Sciences 4(4):55-62.

9. Bagheri S, Rezaie F, Fallahi A, Shahsavari S, Pashaei T. The prevalence and the risk factors associated with tranquilizer abuse in the population with the age of over 18 years in Iran. Chronic Diseases Journal. 2018;6(1):29-35.

10. Momtazi S, Rawson RA. Substance abuse among Iranian high school students. Current opinion in psychiatry. 2010;23(3):221.

11. Roberts RE, Roberts CR, Xing Y. Comorbidity of substance use disorders and other psychiatric disorders among adolescents: Evidence from an epidemiologic survey. Drug and Alcohol Dependence. 2007;88(SUPPL.1):S4-S13.

12. Cerullo MA, Strakowski SM. The prevalence and significance of substance use disorders in bipolar type I and II disorder. Substance Abuse Treatment, Prevention, and Policy. 2007;2(1):29.

13. Cerullo MA, Strakowski SM. The prevalence and significance of substance use disorders in bipolar type I and II disorder. Substance abuse treatment, prevention, and policy. 2007;2(1):1-9.

14. Gattamorta KA, Mena MP, Ainsley JB, Santisteban DA. The comorbidity of psychiatric and substance use disorders among Hispanic adolescents. Journal of dual diagnosis. 2017;13(4):254-63.

15. Molina BSG, Howard AL, Swanson JM, Stehli A, Mitchell JT, Kennedy TM, et al. Substance use through adolescence into early adulthood after childhood-diagnosed ADHD: findings from the MTA longitudinal study. the journal of child psychology and psychiatry. 2018;59(6):692-702.

16. Stinson FS, Ruan WJ, Pickering R, Grant BF. Cannabis use disorders in the USA: Prevalence, correlates and co-morbidity. Psychological Medicine. 2006;36(10):1447-60.

17. Frauenglass S, Routh DK, Pantin HM, Mason CA. Family support decreases influence of deviant peers on Hispanic adolescents' substance use. Journal of Clinical Child Psychology. 1997;26(1):15-23.

18. Hawkins EH. A tale of two systems: Co-occurring mental health and substance abuse disorders treatment for adolescents. Annual review of psychology. 2009;60:197-227.

19. Ghouchani HT, Niknam S, Aminshokravi F, Hojjat SK. Factors related to addiction treatment motivations; validity and reliability of an instrument. Journal of research in health sciences. 2016;16(3):147.

20. Mohammadi MR, Alavi SS, Ahmadi N, Khaleghi A, Kamali K, Ahmadi A, et al. The prevalence, comorbidity and socio-demographic factors of depressive disorder among Iranian children and adolescents: To identify the main predictors of depression. Journal of affective disorders. 2019;247:1-10.

21. Kaufman J, Birmaher B, Brent D, Rao U, Flynn C, Moreci P, et al. Schedule for affective disorders and schizophrenia for school-age children-present and lifetime version (K-SADS-PL): initial reliability and validity data. Journal of the American Academy of Child \& Adolescent Psychiatry. 1997;36(7):980-8.

22. Kaufman B, B., Brent, D., Rao, U., \& Ryan, N. The Schedule for Affective Disorders and Schizophrenia for School-Age Children. University of Pittsburgh Medical Center. . 1996. 
23. Polanczyk GV EM, Aranovich V, Denardin D, da Silva TL, da Conceicao TV. Interrater agreement for the schedule for affective disorders and schizophrenia epidemiological version for school-age children (K-SADSE) Rev Bras Psiquiatr. 2003(25):87-90.

24. Ljubotina D, Galic J, Jukic V. Prevalence and risk factors of substance use among urban adolescents: questionnaire study. Croatian medical journal. 2004;45(1):88-98.

25. Mesic S, Ramadani S, Zunic L, Skopljak A, Pasagic A, Masic I. Frequency of Substance Abuse Among Adolescents. Materia Socio-Medica. 2013;25(4):265-9.

26. Sekulic D, Ostojic M, Ostojic Z, Hajdarevic B, Ostojic L. Substance abuse prevalence and its relation to scholastic achievement and sport factors: an analysis among adolescents of the Herzegovina-Neretva Canton in Bosnia and Herzegovina. BMC Public Health. 2012;12(1):274.

27. Chen WY, Propp J, deLara E, Corvo KN. Child Neglect and Its Association With Subsequent Juvenile Drug and Alcohol Offense. Child and Adolescent Social Work Journal. 2011;28(4):273-90.

28. Gibbons FX, Reimer RA, Gerrard M, Yeh H-C, Houlihan AE, Cutrona C, et al. Rural-Urban Differences in Substance Use Among African-American Adolescents. The Journal of rural health : official journal of the American Rural Health Association and the National Rural Health Care Association. 2007;23(Suppl):22-8.

29. Boogar IR, Tabatabaee SM, Tosi J. Attitude to substance abuse: do personality and socio-demographic factors matter? International journal of high risk behaviors \& addiction. 2014;3(3).

30. Sharma S, Mohite S, Memon A, Hamilton J, Kazimi I. S61. Correlation of Age to Psychotropic Medication Adherence and Substance Abuse in Adolescents With Mental Health Illnesses. Biological Psychiatry. 2018;83(9, Supplement):S370.

31. Pérez A, Osman A, Peña L, Abad-Vivero EN, Hardin JW, Sargent J, et al. Parent Education and Substance Use among Latin American Early Adolescents. Health Behavior and Policy Review. 2018;5(3):91-9.

32. Daniel JZ, Hickman M, Macleod J, Wiles N, Lingford-Hughes A, Farrell M, et al. Is socioeconomic status in early life associated with drug use? A systematic review of the evidence. Drug and alcohol review. 2009;28(2):142-53.

33. Droomers M, Schrijvers CTM, Casswell S, Mackenbach J. Occupational level of the father and alcohol consumption during adolescence; patterns and predictors. Journal of Epidemiology \& Community Health. 2003;57(9):704-10.

34. Vereecken CA, Maes L, De Bacquer D. The influence of parental occupation and the pupils' educational level on lifestyle behaviors among adolescents in Belgium. Journal of Adolescent Health. 2004;34(4):330-8.

35. Richter M, Vereecken CA, Boyce W, Maes L, Gabhainn SN, Currie CE. Parental occupation, family affluence and adolescent health behaviour in 28 countries. International Journal of Public Health. 2009;54(4):203-12.

36. Cambron C, Kosterman R, Catalano RF, Guttmannova K, Hawkins JD. Neighborhood, Family, and Peer Factors Associated with Early Adolescent Smoking and Alcohol Use. Journal of Youth and Adolescence. 2018;47(2):369-82.

37. Minami H, Bloom EL, Brinkman HR, Abrantes AM, Young CC, Brown RA. Factors related to cigarette smoking and intent to quit among adolescent inpatients with psychiatric and substance use disorders. Drug and Alcohol Dependence. 2018;186:215-8.

38. Parker JS, Benson MJ. Parent-adolescent relations and adolescent functioning: self-esteem, substance abuse, and delinquency. Adolescence. 2004;39(155):519-30.

Page 20/21 
39. Ewing BA, Osilla KC, Pedersen ER, Hunter SB, Miles JNV, D'Amico EJ. Longitudinal family effects on substance use among an at-risk adolescent sample. Addictive behaviors. 2015;41:185-91.

40. Nock MK, Green JG, Hwang I, McLaughlin KA, Sampson NA, Zaslavsky AM, et al. Prevalence, correlates, and treatment of lifetime suicidal behavior among adolescents: Results from the national comorbidity survey replication adolescent supplement. JAMA Psychiatry. 2013;9:1-11.

41. Ramchand R, Griffin BA, Harris KM, McCaffrey DF, Morral AR. A Prospective Investigation of Suicide Ideation, Attempts, and Use of Mental Health Service Among Adolescents in Substance Abuse Treatment. Psychology of Addictive Behaviors. 2008;22(4):524-32.

42. Welsh JW, Knight JR, Hou SS-Y, Malowney M, Schram P, Sherritt L, et al. Association between substance use diagnoses and psychiatric disorders in an adolescent and young adult clinic-based population. Journal of Adolescent Health. 2017;60(6):648-52.

43. Razali MM, Kliewer W. Risk and protective factors for recreational and hard drug use among Malaysian adolescents and young adults. Addictive behaviors. 2015;50:149-56.

44. Swendsen J, Conway KP, Degenhardt L, Glantz M, Jin R, Merikangas KR, et al. Mental disorders as risk factors for substance use, abuse and dependence: results from the 10-year follow-up of the National Comorbidity Survey. Addiction. 2010;105(6):1117-28.

45. Rockhill C KI, DiBattisto C, Macias M, Varley C, Ryan S. A. nxiety disorders in children and adolescents. Curr Problems Pediatr Adolesc Health Care arch Gen Psychiatry. 2010;40(4):66-99.

46. Blumenthal H, Taylor DJ, Cloutier RM, Baxley C, Lasslett H. The Links Between Social Anxiety Disorder, Insomnia Symptoms, and Alcohol Use Disorders: Findings From a Large Sample of Adolescents in the United States. Behavior Therapy. 2018.

47. Conway KP, Swendsen J, Husky MM, He JP, Merikangas KR. Association of Lifetime Mental Disorders and Subsequent Alcohol and Illicit Drug Use: Results from the National Comorbidity Survey-Adolescent Supplement. Journal of the American Academy of Child and Adolescent Psychiatry. 2016;55(4):280-8.

48. Legerstee JS, Garnefski, N., Jellesma, F.C., Verhulst, F.C., and Utens, E M. Cognitive coping and childhood anxiety disorders. Eur Child Adolesc Psychiatry 2010;19:143 -50.

49. Magar EC, Phillips LH, Hosie JA. Self-regulation and risk-taking. Personality and individual differences. 2008;45(2):153-9.

50. Quinn PD, Fromme K. Self-regulation as a protective factor against risky drinking and sexual behavior. Psychology of addictive behaviors. 2010;24(3):376.

51. Bizzarri JV, Sbrana A, Rucci P, Ravani L, Massei GJ, Gonnelli C, et al. The spectrum of substance abuse in bipolar disorder: Reasons for use, sensation seeking and substance sensitivity. Bipolar Disorders. 2007;9(3):213-20.

52. Goldstein BI, Strober MA, Birmaher B, Axelson DA, Esposito-Smythers C, Goldstein TR, et al. Substance use disorders among adolescents with bipolar spectrum disorders. Bipolar Disorders. 2008;10(4):469-78.

53. Hunt GE, Malhi GS, Cleary M, Lai HMX, Sitharthan T. Prevalence of comorbid bipolar and substance use disorders in clinical settings, 1990-2015: Systematic review and meta-analysis. Journal of Affective Disorders. 2016;206:331-49. 